\title{
Evaluation of Impact of Social Media Networking on Health Status- An Observational Study
}

\author{
Amanjot Kaur Chauhan ${ }^{1}$, Priyanka Gupta ${ }^{2}$, Rajesh Ranjan ${ }^{3}$ \\ ${ }^{1}$ Assistant Professor, Department of Community Medicine, MMIMSR, Mullana, Ambala, ${ }^{2}$ Assistant professor, Department of Community Medicine, SIMS, \\ Hapur. ${ }^{3}$ Associate Professor, Dept. of Community Medicine, Saraswathi Institute of Medical Sciences, Pilkhuwa, Hapur, UP.
}

\section{Abstract}

Background: Social relationships, which are contingent on access to social networks, promote engagement in social activities and provide access to social support. The present study was conducted to assess the effect of social media on health status. Subjects and Methods: The present study comprised of 1050 subjects of both genders. A questionnaire was designed to acquire information such as number of hours spent on social site, type of sites visualized and effect on general health. Responds were recorded and tabulated. Results: It showed that 70 (6.7\%) subjects used to spend 1 hour/day, 260 (24.7\%) subjects spent 2 hours/day and 720 (68.6\%) used to spend >2 hours/day on social media. The difference was significant $(\mathrm{P}<0.05)$. Most commonly seen site was facebook in 760 subjects, watsapp by 820 , yahoo by 870 , twitter by 252 and instagram by 436 subjects. The difference was significant $(\mathrm{P}<0.05)$. Maximum cases of stress $(344)$ were seen in subjects who spent $>2$ hours/day on social media. Similarly, 240 had loss of concentration, 680 had obesity and 270 had hypertension who spent $>2$ hours/day on social media. Conclusion: Authors observed that as the duration on social media increased, the health related troubles increased. Obesity, hypertension, and stress were commonly seen health problems.

Keywords: Health, Stress, Social Media.

Corresponding Author: Dr. Priyanka Gupta, Assistant professor, Department of Community Medicine, SIMS, Hapur, India.

Received: April 2019

Accepted: April 2019

\section{Introduction}

In the early 2000's, the Web became much more personal as social networking websites were introduced and embraced by the masses. ${ }^{[1]}$ Social networking sites (SNS) are defined as web-based services that allow individuals to construct a public or semi-public profile within a limited system, articulate a list of other users with whom they share a connection, and view and traverse their list of connections and those made by others within the system. The nature and terms of these connections may vary from site to site. ${ }^{[2]}$

In the last ten years, the online world has changed dramatically, thanks to the invention of social media, young men and women now exchange ideas, feelings, personal information, pictures and videos at a truly astonishing rate.

Cognitive functioning plays an important role in determining functional abilities, quality of life and independence in older adults. Although changes in cognitive function such as processing speed, episodic memory and executive functions are typical with normative cognitive ageing, cognitive decline is not a part of healthy ageing. Evidence suggests that cognitive function in older adults may be affected by modifiable risk and protective factors including smoking, poor diet, levels of physical activity, cognitive stimulation and social relationships. With an increasing ageing population, cognitive ageing researchers are prioritising exploration of these lifestyle factors as they may provide a pathway to interventions to prevent cognitive decline or maintain cognitive function in older adults. Of these lifestyle factors, social relationships are of particular interest as improving factors associated with social relationships may offer a relatively simple method of promoting positive outcomes in cognitive functioning.

Seventy-three percent of wired American teens now use social media websites. Social network interventions have been successfully used in international health programs to promote modern family planning methods and bullying reduction among adolescents. ${ }^{[3]}$ Social network focused interventions have been utilized for weight reduction, diabetes, smoking cessation, exercise, and improving the well-being of people with schizophrenia. There has been documentation regarding excessive usage of social networking on general health of individual. The effect of social media on general health is based on various factors such as duration of usage, kind of sites seen etc. ${ }^{[4]}$ The present study was conducted to assess the impact of social media on health status. 


\section{Subjects and Methods}

The present study was conducted in the department of Community Medicine to assess the impact of social media on health status. Ethical approval was obtained from institutional ethical committee. All were informed regarding the study. It comprised of 1050 subjects of both genders.

General information such as name, age, gender etc. was recorded. A questionnaire was designed to acquire information such as number of hours spent on social site, type of sites visualized and effect on general health. Responds were recorded and tabulated. The data was processed and subjected to statistical analysis. $\mathrm{P}$ value less than 0.05 was considered significant.

\section{Results}

\section{Table 1: Distribution of subjects}

\section{Total- 1050}

\begin{tabular}{|l|l|l|}
\hline Gender & Males & Females \\
\hline Number & 630 & 420 \\
\hline
\end{tabular}

[Table 1] shows that out of 1050 subjects, males were 630 and females were 420 .

\section{Table 2: Duration spent on social media}

\begin{tabular}{|l|l|l|}
\hline Duration & Number & P value \\
\hline 1 hour/day & $70(6.7 \%)$ & 0.01 \\
\hline 2 hours/day & $260(24.7 \%)$ & \\
\hline$>2$ hours/day & $720(68.6 \%)$ & \\
\hline
\end{tabular}

[Table 2] shows that $70(6.7 \%)$ subjects used to spend 1 hour/day, $260(24.7 \%)$ subjects spent 2 hours/day and 720 $(68.6 \%)$ used to spend $>2$ hours/day on social media. The difference was significant $(\mathrm{P}<0.05)$.

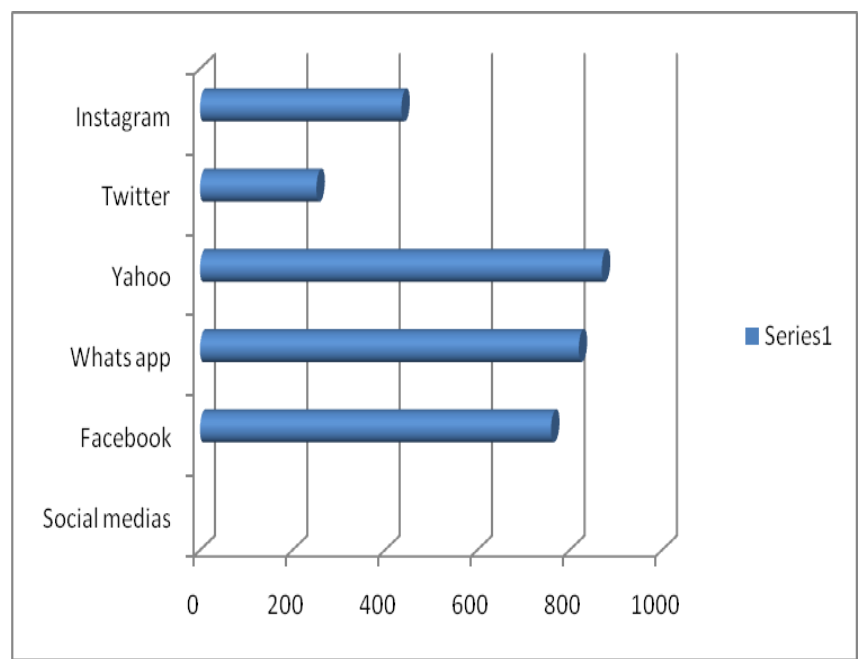

Figure 1: Kind of sites seen

[Figure 1] shows that most commonly seen site was facebook in 760 subjects, watsapp by 820 , yahoo by 870 , twitter by 252 and instagram by 436 subjects. The difference was significant $(\mathrm{P}<0.05)$.
Table 3: Duration on social media and health status

\begin{tabular}{|c|c|c|c|c|}
\hline \multirow[t]{2}{*}{ Duration } & \multicolumn{4}{|c|}{ Health status } \\
\hline & Stress & $\begin{array}{l}\text { Loss of } \\
\text { concentration }\end{array}$ & Obesity & Hypertension \\
\hline 1 hour/day & 80 & 40 & 220 & 50 \\
\hline $\begin{array}{l}2 \\
\text { hours/day }\end{array}$ & 220 & 140 & 330 & 136 \\
\hline $\begin{array}{l}>2 \\
\text { hours/day }\end{array}$ & 344 & 240 & 680 & 270 \\
\hline
\end{tabular}

[Table 3] shows that maximum cases of stress (344) were seen in subjects who spent $>2$ hours/day on social media. Similarly, 240 had loss of concentration, 680 had obesity and 270 had hypertension who spent $>2$ hours/day on social media.

\section{Discussion}

At first glance, it may seem like a surprising notion that social media can affect your health. When we consider how much time people spend engaging on sites such as Facebook, Twitter, Instagram and others, however, it really makes sense. Anything that takes up large amounts of your time, including work, watching TV, exercising or driving, has some impact on your health. The question is whether social media is good or bad for us. The simple answer is that it can be both. Fortunately, there are ways to help reduce its harmful effects while maximizing the benefits. Social networking activity is becoming more endemic in society and yet little is known about how the social comparison, occurring when we use these sites, affects perceptions of health. Network interventions often utilize existing social support, social exchange, and social influence processes such as modeling and verbal persuasion. They utilize the existing network structure to diffuse behavior change. Moreover, as network members often maintain relationships, networks interventions can help to sustain behavior change. For serious illness and health conditions, members of individuals' personal network are often emotionally, economically, and socially impacted. Hence, for secondary prevention it can be helpful to involve and consider these network members in the support, care, and behavior changes processes. ${ }^{[5]}$

As it's known in this generation tend to rely on the net and also spend most of the time on social networking sites such as Twitter, Google Plus, MySpace and Facebook. This is probably due to the reason that college and university students as well as teens used it extensively to get global access. The majority of the scholars prefers to stay on the internet for hours, than studying for their exams or doing their assignments. The main reason is that when they are studying or searching their course material online, they get attracted to SNS's to kill the boredom in their study time, diverting their attention from their work. ${ }^{[6]}$ The present study was conducted to assess the effect of social media on health status.

In our study, out of 1050 subjects, males were 630 and females were 420 . We observed that $70(6.7 \%)$ subjects used to spend 1 hour/day, $260(24.7 \%)$ subjects spent 2 
hours/day and $720(68.6 \%)$ used to spend $>2$ hours/day on social media. The difference was significant $(\mathrm{P}<0.05)$.

Junco et al, ${ }^{[7]}$ conducted a study in which out of one thousand five hundred and seventy-eight copies of the questionnaire distributed, one thousand five hundred and eight were retrieved which represented a response rate of $95.5 \%$. The study revealed that majority of the respondents had mobile phones which also had Internet facility on them and had knowledge of the existence of many media sites. The study further confirmed that most of the respondents visit their social media sites using their phones and spend between thirty minutes to three hours per day. In addition the study revealed that the use of social media sites had affected academic performance of the respondents negatively and that there was direct relationship between the use of social media sites and academic performance. The study recommends among others that, students with mobile phones having internet facility should be encouraged to use it to supplement their research in the library rather than the usual charting with friends all the time. Students should be encouraged to limit the time they spend on their social media sites per day and advise them to rather substitute those hours to read novels to improve their knowledge. Since the use of social media sites had affected the academic work of students negatively there is the urgent need for the introduction of students to the availability of novels and other information resources or materials that can help them academically.

Aida et al, ${ }^{[8]}$ conducted a study in which out of 1215 subjects, 890 had various health issues. A questionnaire was prepared and distributed among subjects to respond accordingly. It was found that those who spent more than 4 hours on social site they tend to have more health problems. Among those, obesity, hypertension, dementia and arthritis was common. The study showed that the use of social media sites had affected academic performance negatively. There was occurrence of dependency on social sites.

When used consciously and in moderation, social media can have a positive impact on your life and even your health. Alex DiRenzo, ${ }^{[9]}$ suggested that use social media at certain scheduled times. Don't let it interfere with your work, studies or offline relationships. If you have difficulty getting off social media, try productivity apps that limit your access to certain sites. If you have a serious addiction problem, seek professional help. Use social media to research health issues, but always consult with your own doctor before taking any advice. Stay off social media and any communications platforms while driving or doing anything else that's potentially hazardous. Stay positive. Don't waste time arguing with people online.

\section{Conclusion}

Authors found that as the duration on social media increased, the health related problems increased. Obesity, hypertension, and stress was commonly seen health problems.

\section{References}

1. Kincaid DL. Social networks, ideation, and contraceptive behavior in bangladesh: A longitudinal analysis. SocSci Med. 2000; 50(2):215231.

2. Wolfer R, Scheithauer H. Social influence and bullying behavior: Intervention-based network dynamics of the fairplayer.manual bullying prevention program. Aggress Behav. 2014; 40(4):309-319.

3. Terzian E, Tognoni G, Bracco R, et al. Social network intervention in patients with schizophrenia and marked social withdrawal: A randomized controlled study. Can J Psychiatry. 2013; 58(11):622-631.

4. Latkin C, Donnell D, Liu TY, Davey-Rothwell M, Celentano D, Metzger D. The dynamic relationship between social norms and behaviors: The results of an HIV prevention network intervention for injection drug users. Addiction. 2013; 108(5):934-943.

5. Bryer, T., \&Zavattaro, S. Social media and public administration: Theoretical dimensions and introduction to symposium Administrative Theory \& Praxis 2011; 33(3): 325-340.

6. Cassidy, E., Britsch, J., Griffin, G., Manolovitz, T., Shen, L., \&Turney, L. Higher education and emerging technologies: Student usage, preferences, and lessons for library services. Reference \& User Services Quarterly 2011; 50(4): 380-391.

7. Junco, R. Too much face and not enough books: The relationship between multiple indices of Facebook use and academic performance. Computers In Human Behavior 2011; 28(1): 187-198.

8. Aida Abdulahi. A Study on the Negative Effects of Social Networking Sites Such as Facebook among Asia Pacific University Scholars in Malaysia International Journal of Business and Social Science. 2014; 5: $1-10$.

9. Alex DiRenzo. How Can Social Media Affect Your Health?[Online available at: https://sysomos.com/2016/10/27/can-social-media-affecthealth/] Last accessed on: 24-02-2019

Copyright: (C) the author(s), 2019. It is an open-access article distributed under the terms of the Creative Commons Attribution License (CC BY 4.0), which permits authors to retain ownership of the copyright for their content, and allow anyone to download, reuse, reprint, modify, distribute and/or copy the content as long as the original authors and source are cited.

How to cite this article: Chauhan AK, Gupta P, Ranjan R. Evaluation of Impact of Social Media Networking on Health Status- An Observational Study.Asian J. Med. Res. 2019;8(2):ME23-ME25.

DOI: dx.doi.org/10.21276/ajmr.2019.8.2.ME08.

Source of Support: Nil, Conflict of Interest: None declared. 